\title{
Article
}

\section{Paper Spray lonization Mass Spectrometry as a Potential Tool for Early Diagnosis of Cervical Cancer}

Mendes, Thais P. P., Pereira, Igor, de Lima, Leomir A. S., MedeirosDe-morais, Camilo De lelis, Neves, Ana C. O. N., Martin, Francis L, Lima, Kássio M. G. and Vaz, Boniek Gontijo

Available at https://clok.uclan.ac.uk/34209/

Mendes, Thais P. P., Pereira, Igor, de Lima, Leomir A. S., Medeiros-De-morais, Camilo De lelis orcid iconORCID: 0000-0003-2573-787X, Neves, Ana C. O. N., Martin, Francis L orcid iconORCID: 0000-0001-8562-4944, Lima, Kássio M. G. and Vaz, Boniek Gontijo (2020) Paper Spray lonization Mass Spectrometry as a Potential Tool for Early Diagnosis of Cervical Cancer. Journal of the American Society for Mass Spectrometry, 31 (8). pp. 1665-1672. ISSN 1044-0305

It is advisable to refer to the publisher's version if you intend to cite from the work. http://dx.doi.org/10.1021/jasms.0c00111

For more information about UCLan's research in this area go to http://www.uclan.ac.uk/researchgroups/ and search for <name of research Group>.

For information about Research generally at UCLan please go to http://www.uclan.ac.uk/research/

All outputs in CLoK are protected by Intellectual Property Rights law, including Copyright law. Copyright, IPR and Moral Rights for the works on this site are retained by the individual authors and/or other copyright owners. Terms and conditions for use of this material are defined in the policies page.

\section{CLoK}

Central Lancashire online Knowledge www.clok.uclan.ac.uk

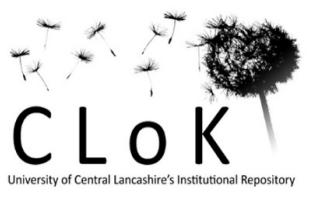




\title{
Paper spray ionization mass spectrometry as a potential tool for early diagnosis of cervical cancer
}

\author{
Thais P. P. Mendes,${ }^{\dagger}$ Igor Pereira, ${ }^{\dagger *}$ Leomir A. S. de Lima,${ }^{\dagger}$ Camilo L. M. Morais, ${ }^{\dagger}$ Ana C. O. N. \\ Menezes, ${ }^{\S}$ Francis L. Martin,,${ }^{\ddagger}$ LJ Kássio M. G. Lima, ${ }^{\S}$ and Boniek Gontijo Vaz ${ }^{\dagger *}$ \\ ${ }^{\dagger}$ Chemistry Institute, Federal University of Goiás, Goiânia, Brazil \\ \$School of Pharmacy and Biomedical Sciences, University of Central Lancashire, Preston, United Kingdom

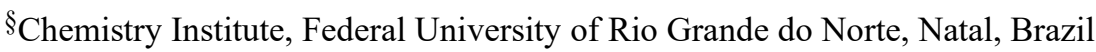 \\ ${ }^{\mathrm{LJ}}$ Instrument Design Laboratory, Biocel Ltd., Hull, United Kingdom
}

\begin{abstract}
Squamous intraepithelial lesion is an abnormal growth of epithelial cells on the surface of the cervix that may lead to cervical cancer. Analytical protocols for the determination of squamous intraepithelial lesions are highly demanded since cervical cancer is the fourth most diagnosed cancer among women in the world. Here, paper spray ionization mass spectrometry (PSI-MS) is used to distinguish between healthy (negative for intraepithelial lesion or malignancy) and diseased (high-grade squamous intraepithelial lesion) blood plasmas. A total of 86 blood samples of different women (healthy $=49$ samples; diseased $=37$ samples) were collected, and the plasmas were prepared. Then, $10 \mu \mathrm{L}$ of each plasma sample was deposited onto triangular papers for PSI-MS analysis. No additional step of sample preparation was necessary. The interval-successive projection algorithm linear discriminant analysis (iSPA-LDA) was applied to the PSI mass spectra, showing six ions (mostly phospholipids) that were predictive of healthy and diseased plasmas. Values of $77 \%$ of accuracy, $86 \%$ of sensitivity, $80 \%$ of PPV, and $75 \%$ of NPV were achieved. This study provides evidence that PSI-MS may potentially be used as a fast and simple analytical technique for early diagnosis of cervical cancer.
\end{abstract}

\section{Keywords: Mass Spectrometry, Ambient Mass Spectrometry, Paper Spray ionization, cervical cancer}

Cervical cancer is the fourth most diagnosed cancer among women in the world. ${ }^{1}$ The incidence of this cancer is higher in lowand middle-income countries than in high-income countries, and one of the main reasons for this is the low quality of cancer screening. ${ }^{2}$ For example, in Brazil, a study ${ }^{3}$ demonstrated that low quality of cervical cancer screening (lack of access, late examination, and lack of guidance) was lower according to the increase in human development index (HDI) and per capita household income, while indigenous women had the highest prevalence of outcomes. Therefore, adequate screening and early diagnosis are essential aspects involved in the progress against cervical cancer.

Historically, the Papanicolaou test, more technically referred to as cytology, has been the most used method for cervical cancer screening. This method is based on discerning normal and malignant cervical cells by viewing swabs smeared on microscopic slides. ${ }^{4}$ However, growing evidence suggests that cytology alone may not be reliable since this method is subjective, and its sensitivity is quite variable (approximately $30-87 \%$ ), with less sensitivity (up to $11 \%$ ) in developing countries. ${ }^{4,7}$ An alternative and more sensitive method for cervical cancer screening is the human papillomavirus (HPV) test, which tests for the presence of the HPV, rather than the tissue changes of cervical cancer. ${ }^{8} \mathrm{HPV}$ infection causes squamous intraepithelial lesions, which are abnormal growths of epithelial cells on the surface of the cervix that may lead to cervical cancer. ${ }^{9}$ These precancerous lesions are classified as low- or high-grade squamous intraepithelial lesions, according to their potentiality to become cervical cancer over time. ${ }^{10}$ The HPV test has been widely used since the discovery that the virus is associated with upward of $95 \%$ of cervical malignancies. ${ }^{8}$ However, due to the high sensitivity, the HPV test is often associated with false-positive outcomes due to the high prevalence of the virus and hence tends to decrease the specificity of screening. ${ }^{11,12}$ Therefore, new methodologies that may complement or even improve current protocols are highly required.

Mass spectrometry-based methods such as gas chromatography coupled to mass spectrometry (GC-MS), liquid chromatography coupled to mass spectrometry (LC-MS), and matrix-assisted laser desorption/ionization (MALDI-MS) are techniques widely used in cancer research due to their ability to determine chemical profiles of tissues or biological fluids (for example, urine or blood serum/plasma) and find biomarkers associated with different types of cancer, ${ }^{13-15}$ including cervical cancer. ${ }^{16-21}$ Although GC-MS and LC-MS provide reliable results with excellent analytical 
performance, both techniques require extensive and arduous sample preparation steps before instrumental analysis, consuming reagents or solvents, and generating chemical waste. On the other hand, MALDI-MS requires the use of a matrix prior to MS analysis, which makes it a time-consuming approach due to the sample preparation steps for mixing and co-crystalizing the sample with the matrix, in addition to making difficult the analysis of small molecules due to the interference of matrix ions in the low $m / z$ region of the mass spectrum. Therefore, analytical methods that require minimal sample preparation, consume less quantity of solvent or sample, and provide adequate chemical profiles for cancer diagnosis are highly desirable.

Ambient mass spectrometry (AMS) techniques have been developed to fulfill the aforementioned requirements, allowing the analysis of compounds directly from their native environment with minimal or no sample preparation. ${ }^{22}$ Desorption electrospray ionization (DESI) ${ }^{23}$ and direct analysis in real-time (DART) ${ }^{4}$ were the first AMS techniques developed, followed by a large number of AMS methods that have been used for direct analysis of a wide range of analytes and samples. ${ }^{25,26}$ Among the AMS techniques, paper spray ionization (PSI) is one of the most simple, inexpensive, and capable of providing results in a short-time analysis. In PSIMS, a triangular paper is used as a substrate to generate analyte ions for MS. The sample is deposited onto the triangular paper, which is subsequently moistened with a solvent. When a high voltage is applied to the paper, a spray with charged droplets is generated at the paper tip and goes towards the mass spectrometer inlet for MS analysis. ${ }^{27}$ The analytical performance of PSI-MS has been evaluated in a wide range of applications including detection of drugs in fingerprint samples ${ }^{28}$ quantifications of pesticides in fruits and vegetables, ${ }^{29,30}$ characterization of energetic polymers, ${ }^{31}$ investigations of inks and questioned documents, ${ }^{32}$ analysis of drugs of abuse, ${ }^{33,34}$ and coupling to portable mass spectrometers for on-site analysis. ${ }^{35}$ In addition, PSI-MS has been widely employed in clinical diagnosis ${ }^{36-43}$ due to its ability to allow biofluid analysis using a small amount of sample with minimal or even no sample preparation (for example, by applying few microliters of plasma, serum, or whole blood directly onto a triangular paper), which can significantly reduce the invasiveness to the patients and waiting time for clinical reports. Consequently, PSI-MS emerges as a potential tool for early diagnosis of cervical cancer.

In this study, we propose, for the first time, the use of PSI-MS as a fast and straightforward method for discriminating between healthy (negative for intraepithelial lesion or malignancy) and diseased (high-grade squamous intraepithelial lesion) blood plasma samples. A total of 86 blood samples of different women (healthy $=49$ samples; diseased $=37$ samples) were collected and submitted to plasma preparation, followed by the deposition of the plasma samples onto triangular papers for MS analysis. No additional step of sample preparation was necessary. In addition, because MS provides such a wealth of chemical information, this technique invites a statistical analysis. Thus, we combined the chemical information provided by the PSI-MS analysis with the intervalsuccessive projection algorithm linear discriminant analysis (iSPALDA) to classify blood plasma as healthy or diseased and also to select those molecular features most indicative of the disease state.

\section{EXPERIMENTAL SECTION}

Collection and preparation of specimens. Women

from the Rio Grande do Norte (Brazil), attending the Januario Cicco Maternity School of the public health system for cervical pathology screening consultations and reference services for colposcopy, were volunteers from July 2014 to March 2016. All volunteers were between 18 and 62 years old (mean age of 37 and 34 for healthy and diseased women, respectively), including whites, blacks, and multiracials. In addition, these women were under varied social/healthy conditions, such as first sexual intercourse, marriage, use of contraceptive methods, and consumption of alcohol and cigarette. The Institutional Ethics Committee for Human Research of the Onofre Lopes University Hospital at the Federal University of Rio Grande do Norte (Brazil) approved this study (protocol \#526/11). Written informed consent was obtained from all subjects. A total of 86 blood samples of different women were collected by venipuncture into tubes containing the anticoagulant ethylenediaminetetraacetic acid (EDTA). Within two hours after blood collection, the plasma was separated by density gradient, and aliquots were transferred into cryogenic tubes and stored at $-80^{\circ} \mathrm{C}$ until analysis. Shortly after blood collection, women were submitted to cytology smears or large-loop excision of the transformation zone (LLETZ). For samples obtained from LLETZ, the histopathological analysis was performed on sections from paraffin blocks in $4 \mu \mathrm{m}$ thickness and stained with hematoxylin/eosin. The histopathological analysis was performed to avoid misleading results from the cytology test, since the latter is well known for its low sensitivity. Cytology and histopathology were reported according to the Bethesda System: ${ }^{44}$ 49 patients diagnosed as negative for intraepithelial lesion or malignancy and 37 patients diagnosed with high-grade squamous intraepithelial lesions.

Paper spray ionization mass spectrometry. The PSI parameters were used according to protocols previously demonstrated by our group. ${ }^{29,30,37,45,46}$ The paper (Whatman \#1, 11 $\mu \mathrm{m}$ pores, purchased from Whatman International Ltd., Maidstone, UK) was cut into an equilateral triangle shape $(1 \mathrm{~cm}$ sides $)$ and held by a metal clip connected to the voltage source of the mass spectrometer. The paper tip was positioned approximately $4 \mathrm{~mm}$ from the mass spectrometer inlet. A volume of $10 \mu \mathrm{L}$ of blood plasma was applied onto the paper. Lower volumes $(2,5$, and $7 \mu \mathrm{L})$ were tested but did not provide satisfactory analyte signals. After the deposition of the sample onto the triangular paper, different drying times were evaluated under open-air conditions and at room temperature $\left(23^{\circ}\right): 0$ (shortly after plasma application), 5, 30, and $60 \mathrm{~min}$. Methanol $(\mathrm{MeOH}), \mathrm{MeOH} / \mathrm{H}_{2} \mathrm{O}(50: 50)$, and acetonitrile $(\mathrm{ACN}) / \mathrm{H}_{2} \mathrm{O}(50: 50)$, all with $0.1 \%$ formic acid, were tested as the spray solvent at a volume of $15 \mu \mathrm{L}$. The analyses were performed in triplicate. Mass spectra were recorded for $1 \mathrm{~min} / \mathrm{sample}^{47}$ using a Thermo Scientific LCQ Fleet ion trap mass spectrometer (San Jose, USA). The positive ionization mode was used throughout the experiment because it provided abundant peaks of lipids, compounds widely studied in cancer diagnostic research.8 The negative ionization mode did not provide detection of lipids and, therefore, it was not used in the experiments. Other instrumental parameters were optimized by varying one variable and fixing all the others, and the best conditions were as follows: scan range: $\mathrm{m} / \mathrm{z}$ 100-1000; spray voltage: $3.5 \mathrm{kV}$; capillary temperature: $275^{\circ} \mathrm{C}$; capillary voltage: $10 \mathrm{~V}$; tube lens: $50 \mathrm{~V}$; activated AGC; maximum injection time: $100 \mathrm{~ms}$; microscans: 2 . The mass spectra were processed using the Xcalibur Analysis software package (Version 2.0, Service Release 2, Thermo Electron Corporation). Each mass spectrum was summed at the total ion current $(1 \mathrm{~min}$ of acquisition), converted to txt file, and used for statistical analysis. 
Identification of ions. Predictive compounds were identified by collision-induced dissociation (CID) experiments using the LCQ Fleet ion trap mass spectrometer. The isolation window was $1 \mathrm{~m} / \mathrm{z}$, and the collision energy ranged from 15 to 30 (manufacturer's unit). Fragmentation patterns were compared to literature reports and compared to data from Lipidmaps (www.lipidmaps.org). Lipids were characterized by fatty acid composition, but the stereochemistry of the chains and double bond position is unknown. In addition, to improve identification of the predictive ions, the plasma samples were analyzed by PSI-MS (same protocol described in the subsection "paper spray ionization mass spectrometer") using a high-resolution Q Exactive ${ }^{\mathrm{TM}}$ hybrid Quadrupole-Orbitrap mass spectrometer (Thermo Scientific, San Jose, USA). Six samples (3 healthy and 3 diseased) were analyzed using Q Exactive, and the chemical profiles were compared to those obtained using the LCQ mass spectrometer. No statistical method was applied to the high-resolution mass spectra. The optimized Q Exactive parameters were as follows: positive ion mode; $\mathrm{m} / \mathrm{z} 500$ 1000; resolution: 140,000; spray voltage: $3.5 \mathrm{kV}$; capillary temperature: $275^{\circ} \mathrm{C}$; S-lens RF Level: $50 \%$; activated AGC; maximum injection time: $100 \mathrm{~ms}$; microscans: 2 .

Statistical analysis. Initially, the spectral data were baseline corrected using the Xcalibur software. In MATLAB (version R2014b environment, MathWorks Inc., Natick, USA), the spectra were mass drift corrected by a lab-made routine to ensure that all mass spectra were the same size and that all peaks were aligned. The alignment of peaks was carried out using an in-house developed algorithm. The alignment was performed with the raw spectra, and the resolution was set at $0.1 \mathrm{~m} / \mathrm{z}$. Subsequently, the spectra were pre-processed by normalization so that the sum of squares of each row (spectrum) was equal to 1 and mean-centered. Before modeling, samples were divided into training $(\sim 70 \%, \mathrm{n}=$ 60 samples: healthy $=35$, diseased $=25)$ and test sets $(\sim 30 \%, \mathrm{n}=$ 26 samples: healthy $=14$, diseased $=12$ ) using the Kennard-Stone sample selection algorithm. The training data were used for model construction and optimization, and the test data for final model evaluation. The percentage ratio of the ion intensities in the mass spectra was employed in the construction of the model. Each spectrum had a final size of $7,040 \mathrm{~m} / \mathrm{z}$ values. The iSPA-LDA method was applied to 7 window intervals, where intervals 1 to 6 were $1006 \mathrm{~m} / \mathrm{z}$ values in size, while interval 7 was $1004 \mathrm{~m} / \mathrm{z}$ values in size. In iSPA-LDA, a successive projection algorithm is applied to the training set in order to reduce the pre-processed data interval to a few numbers of orthogonal variables (i.e., $\mathrm{m} / \mathrm{z}$ values). This is performed by minimizing the average risk of misclassification $\mathrm{G}^{49}$ calculated for each $\mathrm{m} / \mathrm{z}$ window interval in the validation set as:

$G=\frac{1}{N} \sum_{n=1}^{N} g_{n}$

where $N$ is the number of training samples, and $g_{n}$ is defined as:

$g_{n}=\frac{r^{2}\left(x_{n}, m_{I(n)}\right)}{\min _{I(m) \neq I(n)} r^{2}\left(x_{n}, m_{I(m)}\right)}$

where $r^{2}\left(x_{n}, m_{I(n)}\right)$ is the squared Mahalanobis distance between the sample $x_{n}$ and the mean $m_{I(n)}$ of its true class, and $r^{2}\left(x_{n}, m_{I(m)}\right)$ is the squared Mahalanobis distance between the sample $x_{n}$ and the mean $m_{I(m)}$ of the closest wrong class. Finally, a linear discriminant analysis classifier is applied to a matrix that contains the selected variables concatenated from each interval. The performance of the model was evaluated by means of accuracy (total number of samples that are correctly classified considering true and false negatives), sensitivity (proportion of positive tests that are correctly identified), specificity (proportion of negative tests that are correctly identified), positive predictive value (PPV, number of positive tests that are true positives), and negative predictive value (NPV, number of negative tests that are true negatives).$^{50}$ These parameters are calculated as follows:

$$
\begin{aligned}
& \text { Accuracy }(\%)=\left(\frac{\mathrm{TP}+\mathrm{TN}}{\mathrm{TP}+\mathrm{FP}+\mathrm{TN}+\mathrm{FN}}\right) \times 100 \\
& \text { Sensitivity }(\%)=\left(\frac{\mathrm{TP}}{\mathrm{TP}+\mathrm{FN}}\right) \times 100 \\
& \text { Specificity }(\%)=\left(\frac{\mathrm{TN}}{\mathrm{TN}+\mathrm{FP}}\right) \times 100 \\
& \operatorname{PPV}(\%)=\left(\frac{\mathrm{TP}}{\mathrm{TP}+\mathrm{FP}}\right) \times 100 \\
& \operatorname{NPV}(\%)=\left(\frac{\mathrm{TN}}{\mathrm{TN}+\mathrm{FN}}\right) \times 100
\end{aligned}
$$

where TP is defined as true positives, $\mathrm{TN}$ as true negatives, FP as false positives, and $\mathrm{FN}$ as false negatives.

\section{RESULTS AND DISCUSSION}

Initial experiments were carried out to investigate the most appropriate spray solvent. Methanol $(\mathrm{MeOH}), \mathrm{MeOH} / \mathrm{H}_{2} \mathrm{O}$ (50:50), and acetonitrile $(\mathrm{ACN}) / \mathrm{H}_{2} \mathrm{O}(50: 50)$ were tested, and the results are shown in Figure S-1. The analysis was performed by applying 15 $\mu \mathrm{L}$ of the solvent shortly after the application of $10 \mu \mathrm{L}$ of the plasma sample (healthy). A similar profile was achieved between $\mathrm{MeOH}$ and $\mathrm{MeOH} / \mathrm{H}_{2} \mathrm{O}$, and $\mathrm{ACN} / \mathrm{H}_{2} \mathrm{O}$ showed a lower normalized level (NL), with abundant contaminant signals at $\mathrm{m} / \mathrm{z}$ 522 and $\mathrm{m} / \mathrm{z}$ 550. Thus, $\mathrm{MeOH}$ was selected for the subsequent analyses, although $\mathrm{MeOH} / \mathrm{H}_{2} \mathrm{O}$ (50:50) could be successfully employed. Other combinations of solvent systems can also be tested, and this will certainly be considered in future works.

Subsequent experiments were performed to determine how long the blood plasma needs to be dried after its application onto the triangular paper. Figure 1 shows the mass spectra obtained by the PSI-MS analysis of $10 \mu \mathrm{L}$ of a plasma sample (diseased) using the following drying times: 0 (shortly after sample application), 5, 30, and $60 \mathrm{~min}$. The best condition was assessed based on the NL value from the sum of 1 min of acquisition. All the analyses provided mass spectra with satisfactory quality, showing high-intensity ions at the $m / z 700-850$ region, which are typical of lipids. No different ionic species were detected using the different drying times, but small differences in ion intensities were verified, as demonstrated by the NL values in Figure 1. In addition, by checking the extracted ion chromatogram of each abundant ion from 0 to $60 \mathrm{~min}$, the differences in intensities were less than $10 \%$. Since avoiding drying of the sample increases the speed of the PSI-MS analysis, which is highly desirable in clinical diagnosis, the subsequent analyses were performed shortly after the sample application onto the triangular paper.

Posteriorly, PSI-MS was used to analyze 86 samples of blood plasma in order to discriminate between 49 healthy and 37 diseased samples. Ions at the $\mathrm{m} / \mathrm{z} 700-900$ region were detected in both healthy (Figure 2a) and diseased (Figure $2 b$ ) plasmas, but different 
relative abundances were verified. For example, the relative abundances of $m / z 808$ and 834 were higher in healthy samples, whereas the abundances of $m / z 725,782$, and 796 were higher in diseased plasmas. The ion at $\mathrm{m} / \mathrm{z} 579$ was detected only in diseased samples. These results suggest that these ions may be responsible for the differentiation between healthy and diseased plasmas since the difference in relative abundances of ions as a factor to discriminate between normal and cancer samples are very common in ambient MS reports. ${ }^{51-54}$

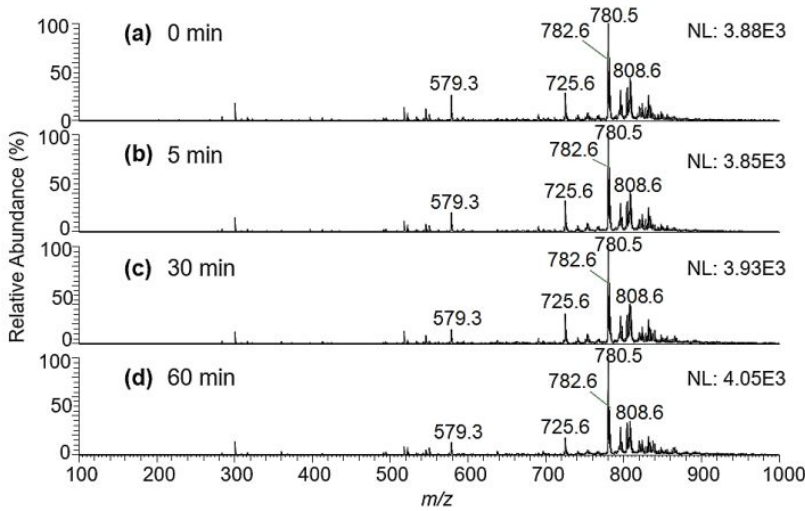

Figure 1. Evaluation of different drying times of a blood plasma sample (diseased) after application of $10 \mu \mathrm{L}$ of sample onto the triangular paper for PSI(+)-MS analysis: (a) 0 (shortly after sample application); (b) $5 \mathrm{~min}$; (c) $30 \mathrm{~min}$; (d) $60 \mathrm{~min}$. NL = normalized level. Each mass spectrum is a sum of 1 min of acquisition.

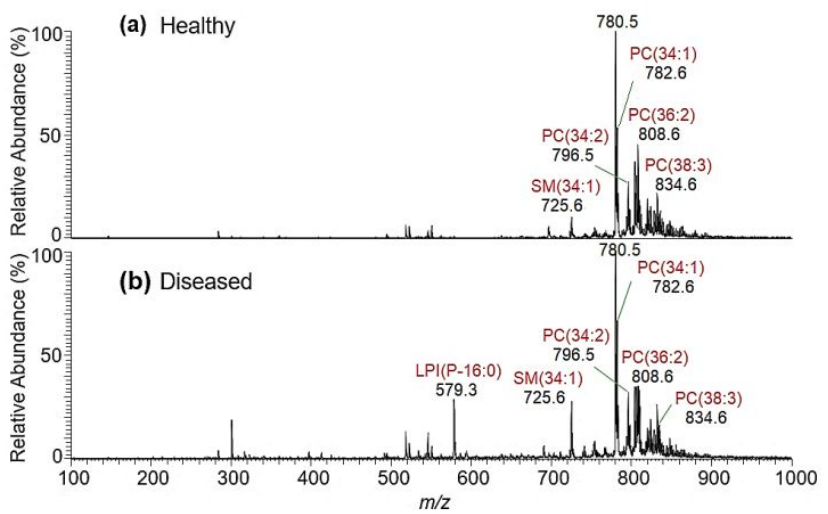

Figure 2. Representative mass spectra obtained by the PSI(+)-MS analysis of (a) healthy and (b) diseased plasmas.

After analyzing all blood plasmas, the iSPA-LDA algorithm was used to evaluate the discrimination between healthy and diseased plasmas and also to identify the molecular features responsible for the discrimination. According to the chemometric model, the six ions mentioned in the previous paragraph were predictive of healthy and diseased plasmas. Detailed information about them is demonstrated in Table 1. Tentative assignments were performed using high-resolution MS, and molecular formulas of sodiated and potassiated lipids were achieved with mass errors below $1 \mathrm{ppm}$. The data were compared to data from Lipidmaps (www.lipidmaps.org). Interestingly, the chemical profiles of healthy and diseased samples obtained by high-resolution MS (Figure S-2) were similar to those obtained by low-resolution MS, which provides evidence that the same compounds were detected using both instruments, avoiding misleading assignments. MS/MS experiments (Figure S-3) were also performed in order to improve identification. Even though the isomerism of the double bonds in the fatty acid chains of complex lipids complicates precise structural assignment, the MS/MS experiments were useful in identifying categories of lipids through the fragmentation patterns that are common to them. For example, losses of trimethylamine ($59 \mathrm{Da})$ and phosphocholine (-183 Da) were helpful in identifying the sphingomyelin (SM) and phosphatidylcholine (PC) lipids 55-58 (see details in Figure S-3). In particular, a concern arises with the lipid LPI(P-16:0), which has not been previously detected in blood plasma samples (as far as we know). The LPI(P-16:0), also known as $\mathrm{PI}(\mathrm{P}-16: 0 / 0: 0)$, is a phosphatidylinositol, a class of lipids popularly known by the acronyms PI followed by the structures of the side chains within parentheses. Several PI lipids (e.g., PI (32:1), PI (34:1), PI (34:2), PI (36:2), PI (36:4), and some others) have already been detected in blood plasma by MS. ${ }^{59}$ The identification of LPI(P-16:0) reported here is not accurate and will require specific identification experiments in future work. Note, however, that not knowing precisely the identity of chemical markers is not an obstacle to using an analytical technique as a potential tool for discrimination between healthy and diseased samples.

Table 1. Values of $m / z$ and mass errors obtained by high-resolution MS, along with proposed molecular formulas, tentative annotations, and relative abundances (low-resolution MS data) of the molecular features responsible for discrimination between healthy and diseased plasmas

\begin{tabular}{|c|c|c|c|c|}
\hline$m / z$ & Error $^{\mathbf{a}}$ & Proposed Formula & $\begin{array}{c}\text { Tentative } \\
\text { annotation }\end{array}$ & $\begin{array}{c}\text { Sample (relative } \\
\text { abundance) }^{\mathbf{b}}\end{array}$ \\
\hline 579.29041 & -0.103 & {$\left[\mathrm{C}_{25} \mathrm{H}_{49} \mathrm{O}_{11} \mathrm{P}+\mathrm{Na}\right]^{+}$} & LPI(P-16:0) & $\begin{array}{c}\text { Diseased }(30 \%) \\
\text { Healthy }(0 \%)\end{array}$ \\
\hline 725.55661 & -0.256 & {$\left[\mathrm{C}_{39} \mathrm{H}_{79} \mathrm{~N}_{2} \mathrm{O}_{6} \mathrm{P}+\mathrm{Na}\right]^{+}$} & $\operatorname{SM}(34: 1)$ & $\begin{array}{c}\text { Diseased }(28 \%) \\
\text { Healthy }(10 \%)\end{array}$ \\
\hline 782.56681 & -0.276 & {$\left[\mathrm{C}_{42} \mathrm{H}_{82} \mathrm{NO}_{8} \mathrm{P}+\mathrm{Na}\right]^{+}$} & $\mathrm{PC}(34: 1)$ & $\begin{array}{c}\text { Diseased }(67 \%) \\
\text { Healthy }(53 \%)\end{array}$ \\
\hline 796.52501 & -0.381 & {$\left[\mathrm{C}_{42} \mathrm{H}_{80} \mathrm{NO}_{8} \mathrm{P}+\mathrm{K}\right]^{+}$} & $\mathrm{PC}(34: 2)$ & $\begin{array}{c}\text { Diseased }(35 \%) \\
\text { Healthy }(27 \%)\end{array}$ \\
\hline 808.58232 & -0.440 & {$\left[\mathrm{C}_{44} \mathrm{H}_{84} \mathrm{NO}_{8} \mathrm{P}+\mathrm{Na}\right]^{+}$} & $\mathrm{PC}(36: 2)$ & $\begin{array}{c}\text { Diseased }(38 \%) \\
\text { Healthy }(45 \%)\end{array}$ \\
\hline 834.59798 & -0.415 & {$\left[\mathrm{C}_{46} \mathrm{H}_{86} \mathrm{NO}_{8} \mathrm{P}+\mathrm{Na}\right]^{+}$} & $\mathrm{PC}(38: 3)$ & $\begin{array}{c}\text { Diseased }(16 \%) \\
\text { Healthy }(24 \%)\end{array}$ \\
\hline
\end{tabular}

${ }^{\mathrm{a} E r r o r}$ in ppm; ${ }^{b}$ relative abundances of predictive ions for healthy and diseased samples.

The iSPA-LDA algorithm was used in this work because the mass spectra data are ill-conditioned due to the high degree of collinearity between the variables and the large number of variables (7,004 variables) in comparison with the small number of samples. This makes impossible the application of LDA directly to spectral data. The use of iSPA as a variable selection technique prior to LDA reduces ill-condition problems since the selected variables have no collinearity. After variable selection, the number of sample spectra will be larger than the number of input variables for LDA, which makes the calculation feasible. 
Figure 3 illustrates the predictions of the plasma samples studied by the iSPA-LDA model. The y-axis represents the calculated response to identify diseased plasmas. A horizontal line was determined from training samples for maximum discrimination between diseased and healthy plasmas. Samples located above the horizontal line are identified as belonging to the diseased group.

The results of the statistical parameters for classification of the plasma samples according to the iSPA-LDA model are shown in Table 2. A value of $77 \%$ of accuracy was achieved, which is a satisfactory value considering the clinical diagnosis since an overall classification error below $25 \%$ was found. The model also showed $86 \%$ sensitivity and $67 \%$ specificity. In addition, the PPV and NPV values were $80 \%$ and $75 \%$, respectively, indicating that the blood plasmas with high-grade squamous intraepithelial lesions (diseased samples) are better classified than healthy plasmas, which suggests that this model may have the potential to be used in early diagnosis of cervical cancer. The confusion matrix for the test set is shown in Table S-1. By using principal component analysis (PCA), no apparent segregation between healthy controls and diseased samples was observed (Figure S-4). Other classification algorithms, such as soft independent modelling of class analogy (SIMCA) and genetic algorithm linear discriminant analysis (GALDA) were also tested, but the iSPA-LDA outperformed them: GA-LDA (test accuracy $=73 \%$ ), SIMCA (test accuracy $=58 \%$ ).

The variables selected by iSPA-LDA are the $m / z$ values with the greatest discriminant power. Hence, these variables are directly associated with cervical cancer diagnosis. The use of PSI-MS with this chemometric approach provides both the classification of samples in an objective fashion and the objective identification of the $m / z$ values responsible for class differentiation, therefore, providing important information about cervical cancer biochemistry.

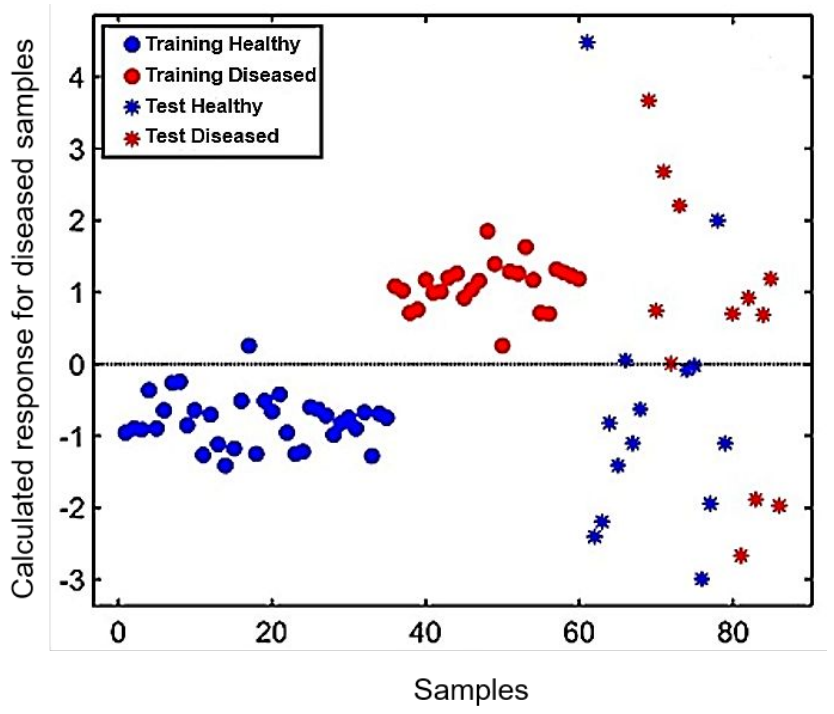

Figure 3. Calculated response of the iSPA-LDA model for the identification of diseased plasma samples. The horizontal line represents a limit for sample discrimination. Samples located above the horizontal line are identified as belonging to the diseased group.

Table 2. Results of the statistical parameters for classification of blood plasma samples according to the iSPA-LDA model

\begin{tabular}{cc}
\hline Parameter & Result (\%) \\
\hline Accuracy & 77 \\
Sensitivity & 86 \\
Specificity & 67 \\
Positive predictive value (PPV) & 80 \\
Negative predictive value (NPV) & 75 \\
\hline
\end{tabular}

The results above are consistent with previous studies that used PSI-MS for discrimination between healthy and cancerous samples. For example, Wang et al. ${ }^{60}$ used PSI-MS for analysis of human prostate tumor tissue and healthy tissue. The authors detected sodiated and potassiated phospholipids such as sphingomyelins (SM) and phosphatidylcholines (PC) in both tissues with distinctive relative abundances. Recently, Huang et al. ${ }^{36}$ combined PSI-MS to machine learning to distinguish between benign and malignant breast biopsies. Different categories of lipids such as phosphatidylethanolamines (PE), sphingomyelins (SM), and phosphatidylcholines (PC) were detected as sodiated and potassiated ions and were employed for discrimination between the samples. In addition, our results are consistent with reports using an ambient ionization technique similar to PSI, called tissue spray ionization. In this technique, the tissue is cut into a small piece and placed in front of the mass spectrometer for direct ionization, instead of placing it onto a triangular paper. Liu et al. ${ }^{51}$ applied the tissue spray technique for the analysis of a variety of organs, including brain, liver, kidney, adrenal gland, stomach, and spinal cord. Wei et al52 used tissue spray for discrimination between human lung squamous cell carcinoma and adjacent normal lung tissues. Kononikhin et al57 reported the use of tissue spray for analysis of human brain tumors.

\section{CONCLUSION}

Paper spray ionization mass spectrometry (PSI-MS) was used for discrimination between healthy (negative for intraepithelial lesion or malignancy) and diseased (high-grade squamous intraepithelial lesion) blood plasma samples. Minimum sample preparation was necessary since lipid ions with high intensities were detected in the mass spectra after the application of few microliters $(10 \mu \mathrm{L})$ of blood plasma onto a triangular paper. In addition, the analyses were relatively fast, since the sample drying step was not necessary. Each analysis took approximately 90 seconds: $\sim 30$ seconds to position the triangular paper in front of the mass spectrometer and apply the sample and solvent onto the paper, and 60 seconds to acquire the data. The method was also quite reproducible, since huge differences in lipid intensities were observed only between the diseased and healthy samples. Samples from the same disease state showed insignificant variations in the intensities of the predictive ions. Using the interval-successive projection algorithm linear discriminant analysis (iSPA-LDA), six ions were determined as responsible for the discrimination between healthy and diseased samples. The predictive ions were tentatively identified mostly as phospholipids, such as sphingomyelins (SM) and phosphatidylcholines (PC). The current approach showed satisfactory accuracy $(77 \%)$ and high sensitivity $(86 \%)$, in addition to providing high values of prevalence $(80 \%$ for PPV and $75 \%$ for NPV). Although a high-resolution mass spectrometer (Q Exactive hybrid Quadrupole-Orbitrap) was used to improve the 
identification of the predictive ions, a low-resolution (LCQ Fleet ion trap) was used to discriminate the samples. The LCQ Fleet mass spectrometer is much cheaper and more common in mass spectrometry laboratories than the Q Exactive, especially in developing countries. The development of protocols using lowresolution mass spectrometers, if possible, is highly desirable. Finally, as the diseased plasmas analyzed in this study are samples with precancerous lesions that can potentially become cervical cancer over time, the combination of PSI-MS with the iSPA-LDA model emerges as a potential tool for early diagnosis of cervical cancer. This approach opens an avenue for rapid and simple analysis of diseased blood plasmas that could be complementary to cytology or HPV test.

\section{ASSOCIATED CONTENT}

\section{Supporting Information}

Supporting Information is available free of charge on the ACS Publications website.

High-resolution mass spectra of healthy and diseased blood plasmas; PSI-MS/MS spectra of representative features that contribute to the discrimination between healthy and diseased plasmas.

\section{AUTHOR INFORMATION}

\author{
Corresponding Author \\ Boniek G. Vaz \\ *E-mail: boniek@ufg.br \\ Igor Pereira \\ *E-mail: ipsigorpereira@gmail.com
}

\section{ORCID}

Boniek G. Vaz: 0000-0003-1197-4284

\section{Author Contributions}

All authors have given approval to the final version of the manuscript.

\section{Notes}

Francis L. Martin declares competing financial interest.

Thais P. P. Mendes, Igor Pereira, Leomir A. S. de Lima, Camilo L. M. Morais, Ana C. O. N. Mene-zes, Kássio M. G. Lima and Boniek Gontijo Vaz declare no competing financial interest.

\section{ACKNOWLEDGMENT}

This material is based upon work supported by the Brazilian Federal Agency for Support and Evaluation of Graduate Education (CAPES) and the Brazilian National Council for Scientific and Technological Development (CNPq).

\section{REFERENCES}

(1) Vu, M.; Yu, J.; Awolude, O. A.; Chuang, L. Cervical cancer worldwide. Curr. Probl. Cancer 2018, 42, 457-465.

(2) Arbyn, M.; Weiderpass, E.; Bruni, L.; Sanjosé, S. de; Saraiya, M.; Ferlay, J.; Bray, F. Estimates of incidence and mortality of cervical cancer in 2018: a worldwide analysis. Lancet Glob. Health 2020, 8, 191-203.
(3) Barcelos, M. R. B.; Lima, R. de C. D.; Tomasi, E.; Nunes, B. P.; Duro, S. M. S.; Facchini, L. A. Quality of cervical cancer screening in Brazil: external assessment of the PMAQ. Rev. Saúde Pública 2017, 51, 67-79.

(4) Bedell, S. L.; Goldstein, L. S.; Goldstein, A. R.; Goldstein, A. T. Cervical cancer screening: past, present, and future. Sex. Med. Rev. 2020, 8, 28-37.

(5) Nanda, K.; McCrory, D. C.; Myers, E. R.; Bastian, L. A.; Hasselblad, V.; Hickey, J. D.; Matchar, D. B. Accuracy of the Papanicolaou test in screening for and follow-up of cervical cytologic abnormalities: a systematic review. Ann. Intern. Med. 2000, 132, 810-819.

(6) Soost, H. J.; Lange, H. J.; Lehmacher, W.; Ruffing-Kullmann, B. The validation of cervical cytology. Sensitivity, specificity and predictive values. Acta Cytol. 1991, 35, 8-14.

(7) Fahey, M. T.; Irwig, L.; Macaskill, P. Meta-analysis of pap test accuracy. Am. J. Epidemiol. 1995, 141, 680-689.

(8) Rizzo, A. E.; Feldman, S. Update on primary HPV screening for cervical cancer prevention. Curr. Probl. Cancer. 2018, 42, 507-520.

(9) Berti, F. C. B.; Salviano-Silva, A.; Beckert, H. C.; de Oliveira, K. B.; Cipolla, G. A.; Malheiros, D. From squamous intraepithelial lesions to cervical cancer: circulating microRNAs as potential biomarkers in cervical carcinogenesis. BBA - Reviews on Cancer 2019, $1872,188306$.

(10) Mehta, S.; Singla, A. Preventive oncology for the gynecologist, 1st ed.; Springer: Singapore, 2019.

(11) Rebolj, M.; Njor, S. H.; Lynge, E. Restriction of human papillomavirus DNA testing in primary cervical screening to women above age 30: systematic review. Eur. J. Cancer Prev. 2012, 21, 73-81.

(12) Del Mistro, A.; Frayle, H.; Ferro, A.; Callegaro, S.; Del Sole, A.; Stomeo, A.; Cirillo, E.; Fedato, C.; Pagni, S.; Barzon, L.; Zorzi, M. Cervical cancer screening by high risk HPV testing in routine practice: results at one year recall of high risk HPV-positive and cytology-negative women. J. Med. Screen. 2014, 21, 30-7.

(13) Liesenfeld, D. B.; Habermann, N.; Owen, R. W.; Scalbert, A.; Ulrich, C. M. Review of mass spectrometry-based metabolomics in cancer research. Cancer Epidemiol. Biomarkers Prev. 2013, 22, 2182-2201.

(14) Fujii, K.; Nakamura, H.; Nishimura, T. Recent mass spectrometry-based proteomics for biomarker discovery in lung cancer, COPD, and asthma. Expert Rev. Proteomic. 2017, 14, $373-386$.

(15) Bandu, R.; Mok, H. J.; Kim, K. P. Phospholipids as cancer biomarkers: mass spectrometry-based analysis. Mass Spectrom. Rev. 2018, 37, 107-138.

(16) Godoy-Vitorino, F.; Ortiz-Morales, G.; Romaguera, J.; Sanchez, M. M.; Martinez-Ferrer, M.; Chorna, N. Discriminating high-risk cervical Human Papilloma Virus infections with urinary biomarkers via non-targeted GC-MS-based metabolomics. PLoS One 2018, 13, 1-14.

(17) Guerrero-Flores, H.; Apresa-García, T.; Garay-Villar, Ó.; Sánchez-Pérez, A.; Flores-Villegas, D.; Bandera-Calderón, A.; García-Palacios, R.; Rojas-Sánchez, T.; Romero-Morelos, P.; Sánchez-Albor, V.; Mata, O.; Arana-Conejo, V.; Badillo-Romero, J.; Taniguchi, K.; Marrero-Rodríguez, D.; Mendoza-Rodríguez, M.; Rodríguez-Esquivel, M.; Huerta-Padilla, V.; MartínezCastillo, A.; Hernández-Gallardo, I.; López-Romero, R.; Bandala, C.; Rosales-Guevara, J.; Salcedo, M. A non-invasive tool for detecting cervical cancer odor by trained scent dogs. BMC Cancer 2017, 17, 1-8. 
(18) Porcari, A. M.; Negrão, F.; Tripodi, G. L.; Pitta, D. R.; Campos, E. A.; Montis, D. M.; Martins, A. M. N.; Eberlin, M. N.; Derchain, S. F. M. Molecular signatures of high-grade cervical lesions. Front. Oncol. 2018, 8, 1-9.

(19) Khan, I.; Nam, M.; Kwon, M.; Seo, S.-S.; Jung, S.; Han, J. S.; Hwang, G.-S.; Kim, M. K. LC/MS-based polar metabolite profiling identified unique biomarker signatures for cervical cancer and cervical intraepithelial neoplasia using global and targeted metabolomics. Cancers 2019, 11, 1-20.

(20) Schwamborn, K.; Krieg, R. C.; Uhlig, S.; Ikenberg, H.; Wellmann, A. MALDI imaging as a specific diagnostic tool for routine cervical cytology specimens. Int. J. Mol. Med. 2011, 27, 417-421.

(21) Liu, C.; Pan, C.; Shen, J.; Wang, H.; Yong, L.; Zhang, R. Discrimination analysis of mass spectrometry proteomics for cervical cancer detection. Med. Oncol. 2011, 28, 553-559.

(22) Cooks, R. G.; Ouyang, Z.; Takats, Z.; Wiseman, J. Ambient mass spectrometry. Science 2006, 311, 1566-1570.

(23) Takáts, Z.; Wiseman, J. M.; Gologan, B.; Cooks, R. G. (2004). Mass spectrometry sampling under ambient conditions with desorption electrospray ionization. Science 2004, 306, 471-473.

(24) Cody, R. B.; Laramée, J. A.; Durst, H. D. Versatile new ion source for the analysis of materials in open air under ambient conditions. Anal. Chem. 2005, 77, 2297-2302.

(25) Shelley, J. T.; Badal, S. P.; Engelhard, C.; Hayen, H. Ambient desorption/ionization mass spectrometry: evolution from rapid qualitative screening to accurate quantification tool. Anal. Bioanal. Chem. 2018, 410, 4061-4076.

(26) Feider, C. L.; Krieger, A.; DeHoog, R. J.; Eberlin, L. S. Ambient ionization mass spectrometry: recent developments and applications. Anal. Chem. 2019, 91, 4266-4290.

(27) Wang, H.; Liu, J.; Cooks, R. G.; Ouyang, Z. Paper spray for direct analysis of complex mixtures using mass spectrometry. Angew. Chem. Int. Ed. 2010, 49, 877-880.

(28) Costa, C.; Webb, R.; Palitsin, V.; Ismail, M.; de Puit, M.; Atkinson, S.; Bailey, M. J. Rapid, secure drug testing using fingerprint development and paper spray mass spectrometry. Clin. Chem. 2017, 63, 1745-1752.

(29) Pereira, I.; Rodrigues, S. R. M.; de Carvalho, T. C.; Carvalho, V. V.; Lobón, G. S.; Bassane, J. F. P.; Domingos, E.; Romão, W.; Augusti, R.; Vaz, B. G. Rapid screening of agrochemicals by paper spray ionization and leaf spray mass spectrometry: which technique is more appropriate? Anal Methods 2016, 8, 6023-6029.

(30) Moura, A. C. M.; Lago, I. N.; Cardoso, C. F.; dos Reis Nascimento, A.; Pereira, I.; Vaz, B. G. Rapid monitoring of pesticides in tomatoes (Solanum lycopersicum L.) during preharvest intervals by paper spray ionization mass spectrometry. Food Chem. 2020, 310, 125938.

(31) Muyizere, T.; Zheng, Y.; Liu, H.; Zhao, J.; Li, H.; Lu, X.; Austin, D. E.; Zhang, Z. Metal salt assisted electrospray ionization mass spectrometry for the soft ionization of GAP polymers in negative ion mode. Analyst 2020, 145, 34-45.

(32) Domingos, E.; de Carvalho, T. C.; Pereira, I.; Vasconcelos, G. A.; Thompson, C. J.; Augusti, R.; Rodrigues, R. R. T.; Tose, L. V.; Santos, H.; Araujo, J. R.; Vaz, B. G.; Romão, W. Paper spray ionization mass spectrometry applied to forensic chemistry - drugs of abuse, inks and questioned documents. Anal. Methods 2017, 9, 4400-4409.

(33) Tavares, L. S.; Carvalho, T. C.; Romão, W.; Vaz, B. G.; Chaves, A. R. Paper spray tandem mass spectrometry based on molecularly imprinted polymer substrate for cocaine analysis in oral fluid. J. Am. Soc. Mass Spectrom. 2018, 29, 566-572.

(34) Maciel, L. I. L.; Carvalho, T. C.; Pereira, I.; Vaz, B. G. Determination of designer drugs in saliva by paper spray mass spectrometry. Quim. Nova 2019, 42, 676-682.

(35) da Silva, L. C.; Pereira, I.; de Carvalho, T. C.; Filho, J. F. A.; Romão, W.; Vaz, B. G. Paper spray ionization and portable mass spectrometers: a review. Anal. Methods 2019, 11, 999-1013.

(36) Huang, Y.-C.; Chung, H.-H.; Dutkiewicz, E. P.; Chen, C.-L.; Hsieh, H.-Y.; Chen, B.-R.; Wang, M.-Y.; Hsu, C.-C. Predicting breast cancer by paper spray ion mobility spectrometry mass spectrometry and machine learning. Anal. Chem. 2020, 92, $1653-1657$.

(37) Mendes, T. P. P.; Pereira, I.; Ferreira, M. R.; Chaves, A. R.; Vaz, B. G. Molecularly imprinted polymer-coated paper as a substrate for highly sensitive analysis using paper spray mass spectrometry: quantification of metabolites in urine. Anal. Methods 2017, 9, 6117-6123.

(38) Chen, S.; Wan, Q.; Badu-Tawiah, A. K. Mass spectrometry for paper-based immunoassays: toward on-demand diagnosis. $J$. Am. Chem. Soc. 2016, 138, 6356-6359.

(39) Yang, Q.; Wang, H.; Maas, J. D.; Chappell, W. J.; Manicke, N. E.; Cooks, R. G.; Ouyang, Z. Paper spray ionization devices for direct, biomedical analysis using mass spectrometry. Int. J. Mass Spectrom. 2012, 312, 201-207.

(40) Zhang, W.; Wang, X.; Xia, Y.; Ouyang, Z. Ambient ionization and miniature mass spectrometry systems for disease diagnosis and therapeutic monitoring. Theranostics. 2017, 7, 2968-2981.

(41) Lin, C.-H.; Liao, W.-C.; Chen, H.-K.; Kuo, T.-Y. Paper spray-MS for bioanalysis. Bioanalysis 2014, 6, 199-208.

(42) Yannell, K. E.; Kesely, K. R.; Chien, H. D.; Kissinger, C. B.; Cooks, R. G. Comparison of paper spray mass spectrometry analysis of dried blood spots from devices used for in-field collection of clinical samples. Anal. Bioanal. Chem. 2017, 409, 121-131.

(43) Chiang, S.; Zhang, W.; Ouyang, Z. Paper spray ionization mass spectrometry: recent advances and clinical applications. Expert Rev. Proteomic. 2018, 15, 781-789.

(44) Nayar, R.; Wilbur, D. The Bethesda System for reporting cervical cytology: definitions, criteria, and explanatory notes, $3 \mathrm{rd}$ ed.; Springer: New York, 2015.

(45) Pereira, I.; de Carvalho, T. C.; Romão, W.; Filgueiras, P. R.; Laviola, B. G.; Rodrigues, C. M.; Abdelnur, P. V.; Vaz, B. G. Differentiation of toxic and non-toxic leaves of Jatropha curcas L. genotypes by leaf spray mass spectrometry. J. Braz. Chem. Soc. 2017, 28, 1461-1466.

(46) Pereira, I.; Rodrigues, M. F.; Chaves, A. R.; Vaz, B. G. Molecularly imprinted polymer (MIP) membrane assisted direct spray ionization mass spectrometry for agrochemicals screening in foodstuffs. Talanta 2018, 178, 507-514.

(47) Hamid, A. M.; Jarmusch, A. K.; Pirro, V.; Pincus, D. H.; Clay, B. G.; Gervasi, G.; Cooks, R. G. Rapid discrimination of bacteria by paper spray mass spectrometry. Anal. Chem. 2014, 86 , $7500-7507$.

(48) Perrotti, F.; Rosa, C.; Cicalini, I.; Sacchetta, P.; Del Boccio, P.; Genovesi, D.; Pieragostino, D. Advances in lipidomics for cancer biomarkers discovery. Int. J. Mol. Sci. 2016, 17, 1-26.

(49) Costa, F. S. L.; Silva, P. P.; Morais, C. L. M.; Arantes, T. D.; Milan, E. P.; Theodoro, R. C.; Lima, K. M. G. Attenuated total reflection Fourier transform-infrared (ATR-FTIR) spectroscopy as a new technology for discrimination between Cryptococcus 
neoformans and Cryptococcus gattii. Anal. Methods 2016, 8, 71077115 .

(50) Ballabio, D.; Consonni, V. Classification tools in chemistry. Part 1: linear models. PLS-DA. Anal. Methods 2013, 5, 3790-3798. (51) Liu, J.; Cooks, R. G.; Ouyang, Z. Biological tissue diagnostics using needle biopsy and spray ionization mass spectrometry. Anal. Chem. 2011, 83, 9221-9225.

(52) Wei, Y.; Chen, L.; Zhou, W.; Chingin, K.; Ouyang, Y.; Zhu, T.; Wen, H.; Ding, J.; Xu, J.; Chen, H. Tissue spray ionization mass spectrometry for rapid recognition of human lung squamous cell carcinoma. Sci. Rep. 2014, 5, 1-7.

(53) Zhang, J.; Rector, J.; Lin, J. Q.; Young, J. H.; Sans, M.; Katta, N.; Giese, N.; Yu, W.; Nagi, C.; Suliburk, J.; Liu, J.; Bensussan, A.; DeHoog, R. J.; Garza, K. Y.; Ludolph, B.; Sorace, A. G.; Syed, A.; Zahedivash, A.; Milner, T. E.; Eberlin, L. S. Nondestructive tissue analysis for ex vivo and in vivo cancer diagnosis using a handheld mass spectrometry system. Sci. Transl. Med. 2017, 9, 1-7.

(54) Feider, C. L.; Woody, S.; Ledet, S.; Zhang, J.; Sebastian, K.; Breen, M. T.; Eberlin, L. S. Molecular imaging of endometriosis tissues using desorption electrospray ionization mass spectrometry. Sci. Rep. 2019, 9, 1-11.
(55) Houjou, T.; Yamatani, K.; Nakanishi, H.; Imagawa, M.; Shimizu, T.; Taguchi, R. Rapid and selective identification of molecular species in phosphatidylcholine and sphingomyelin by conditional neutral loss scanning and $\mathrm{MS}^{3}$. Rapid Commun. Mass Spectrom. 2004, 18, 3123-3130.

(56) Han, X. Lipidomics: comprehensive mass spectrometry of lipids, 1st ed.; John Wiley \& Sons: Hoboken, 2016.

(57) Kononikhin, A.; Zhvansky, E.; Shurkhay, V.; Popov, I.; Bormotov, D.; Kostyukevich, Y.; Karchugina, S.; Indeykina, M.; Bugrova, A.; Starodubtseva, N.; Potapov, A.; Nikolaev, E. A novel direct spray-from-tissue ionization method for mass spectrometric analysis of human brain tumors. Anal. Bioanal. Chem. 2015, 407, $7797-7805$

(58) Manicke, N. E.; Wiseman, J. M.; Ifa, D. R.; Cooks, R. G. Desorption electrospray ionization (DESI) mass spectrometry and tandem mass spectrometry (MS/MS) of phospholipids and sphingolipids: ionization, adduct formation, and fragmentation. $J$. Am. Soc. Mass Spectrom. 2008, 19, 531-543.

(59) Cajka, T.; Fiehn, O. LC/MS method for comprehensive analysis of plasma lipids. Agilent 2018, 1-10.

(60) Wang, H.; Manicke, N. E.; Yang, Q.; Zheng, L.; Shi, R.; Cooks, R. G.; Ouyang, Z. Direct analysis of biological tissue by paper spray mass spectrometry. Anal. Chem. 2011, 83, 1197-1201.

\section{Table of Contents}

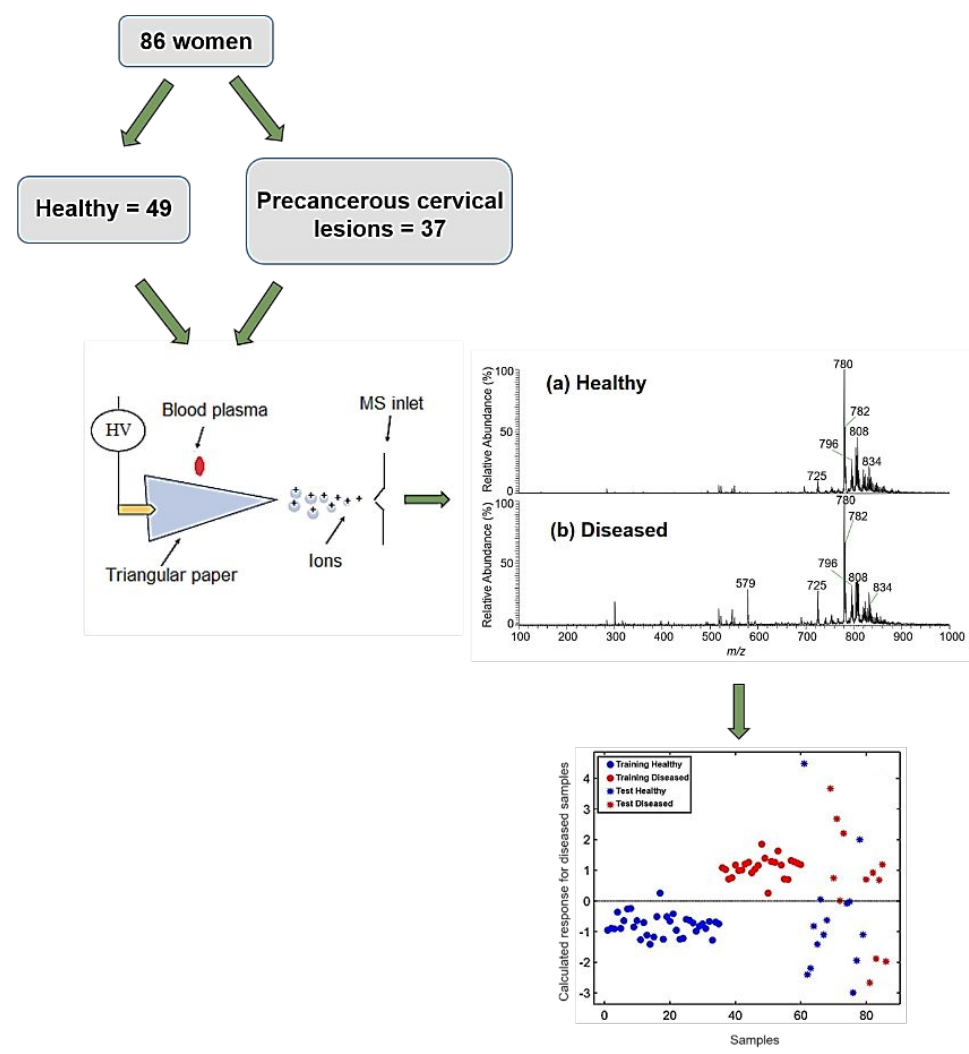

